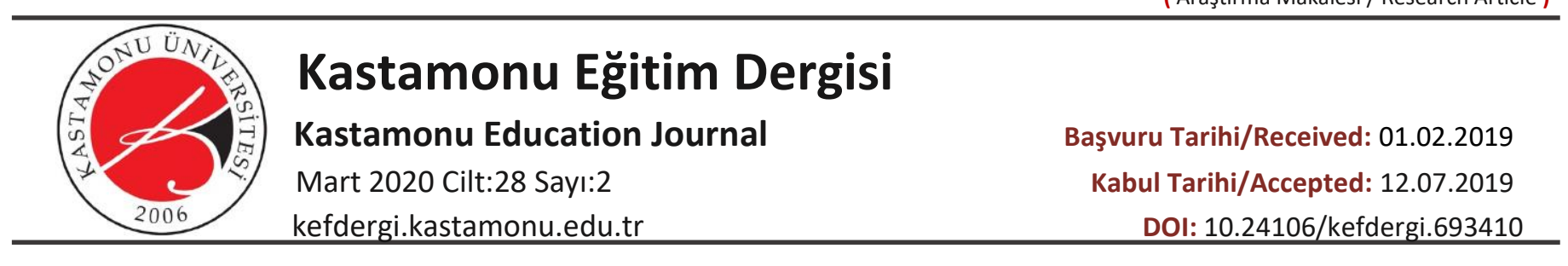

\title{
Akran Zorbalığı ve Travma Sonrası Stres Bozukluğu Arasındaki ilişkinin Gözden Geçirilmesi
}

\section{A Review on the Relationship Between Peer Bullying and Post- Traumatic Stress Disorder}

\author{
Tuğba Türk KURTÇA ${ }^{1}$, Eda ERMAĞAN ÇAĞLAR², Yasemin SANAL ÖZCAN³
}

\section{Öz}

Akran zorbalığı, her geçen yıl artış gösteren bir olgu olarak karşımıza çıkmaktadır. Konuya ilişkin davranışların sıklığında gözlenen artış uzmanların da dikkatini çekmiş; zorbalık davranışının hem zorbalığı uygulayan hem de zorbalığa maruz kalan taraflar açısından etkilerinin saptanmasına yönelik çalışmaların sayısı artmıştır. Ancak, travmaya ilişkin çoklu belirtilerin gözlenebildiği travma sonrası stres bozukluğu ile akran zorbalığı arasındaki ilişkiyi ortaya koyan çalışmaların sınırlı olduğu görülmektedir. Buradan hareketle akran zorbalığı ve akran zorbalığına bağlı ortaya çıkan travmatik sonuçlar arasındaki ilişkinin ele alındığı bu derleme çalışmasında; travmatik semptomların ortaya çıkışında zorbalık olgusunun etkisine ve ilgili semptomların mağdurlar, zorbalar ve zorba/mağdurlar arasında görülme sıklı̆ı̆na dikkat çekmek amaçlanmaktadır.

Anahtar Kelimeler: Akran zorbalığı, akran mağduriyeti, travma, önleme

\section{Abstract}

Peer bullying is a crucial phenomenon that increases every year among children and adolescents. In recent years, the increase in the frequency of behaviors related to peer bullying has attracted the attention of the experts; in connection with the number of studies to determine the effects of the bullying on both the bully and victim has increased. However, it is seemed that number of current researches discussing the relationship between bullying and post-traumatic stress disorder is limited. For these reasons, purpose of this literature review was decided to point out the results of bullying within the context of traumatic symptoms.

Keywords: Peer bullying, peer victimization, trauma, prevention

${ }^{1}$ Trakya Üniversitesi, Eğitim Fakültesi, Psikolojik Danışmanlık ve Rehberlik Bölümü, Edirne, Türkiye. https://orcid.org/0000-0002-4361-3769 ${ }^{2}$ University of Northampton, Faculty of Health, Education \& Society, Department of Psychology, Northampton, UK. https://orcid.org/0000-0002-9690-2898 ${ }^{3}$ Manisa Celal Bayar Üniversitesi, Fen Edebiyat Fakültesi, Psikoloji Bölümü, Manisa, Türkiye. https://orcid.org/0000-0002-3147-6269 


\section{Extended Abstract}

Introduction: Peer bullying among school children and adolescents is a phenomenon that increases with each passing year. A child can be a victim, a bully or both a victim and a bully in peer bullying. In parallel with the increase in bullying, there is an increase in studies executed with the young population on both bullying and its results. The current study was carried out through a systematic review of these studies.

Purpose: The main purpose is to examine population-based, trauma-related scientific articles on peer bullying that were published in peer-reviewed journals; to reveal the relationship between the bullying and the traumatic consequences of bullying.

Method: The method of current study is systematic literature review. PsycINFO, ERIC, ScienceDirect and PubMed were investigated to gather relevant scientific studies. As Turkish language studies on children and adolescents in regard to the scope were not available, search was limited to literature in English. In the searching process, "bullying", "bullied", "peer victimization", "harassment", "trauma", "post traumatic stress symptoms", "stresfull life event" "child" "adolescent" were decided to be used as keywords.

Findings: When the related literature is examined in terms of peer bullying, many descriptions and definitions that are mainly similar to each other but differ from each other in details were found in different studies. Through these studies and definitions, it has been seen that some criteria seem to stand out about peer bullying. The conduct of the behaviour in a deliberate and conscious manner, consciously intent to cause harm, repetitive behaviour, the power imbalance between the victim and the bully, the victim is unable to protect him/herself, the victim is exposed to mild or severe trauma, the bully profits from the behaviour, the bully feels pleasure of the oppressive behaviour seem to be some of these criteria's (Cocuga Yonelik Siddetin Onlenmesi Projesi, 2015; Nazir and Piskin, 2015).

According to the definitions, it is seen that peer bullying is a different way of violence and it can be divided into various types such as physical, social, verbal and cyber. However, peer bullying, regardless of type, causes negative consequences for individuals who are/were experiencing peer bullying in both short and long term. Especially traumatic symptoms with various indications are seemed to be associated with bullying. The information obtained from the literature correlates increased anxiety (Brendgen and Poulin, 2018; Eastman et al.; 2018; Lee and Vaillancourt, 2018) and anxiety related mood disorders, decreased self confidence levels, social withdrawal, stress reactions related to loneliness and behavioural change (Hamilton et al., 2008; Tsaousis, 2016); sleep disorders (van Geel et al., 2016); and psychotic symptoms (Arseneault, Bowes and Shakoor, 2010; van Dam et al., 2012) with peer bullying. And all these experiences are also found to be related to post traumatic stress disorder. Studies with adolescents exposed to bullying by their peers indicate that bullying poses a risk of depression, suicidal ideation and suicide attempts (Baldry \& Winkel, 2003; Brunstein Klomek Marrocco, Kleinman, Schonfeld, and Gould, 2008; Castellví et al., 2017; Holt et al., 2015; Van Geel et al., 2014). It was also found that there is a relationship between exposure to peer bullying during high school and trauma/stress symptoms; and isolation had a mediating effect on the relation (Newman, Holden, and Delville, 2005).Therefore, it has been seen that peer bullying is not a process that individuals experience only in early ages but also in puberty and teen hood. The experiences in later ages seem to have all the dramatic consequences of the phenomenon, as well. In a study conducted with adults exposed to peer bullying in childhood by Takizawa, Maughan and Arseneault (2014) showed that these adults showed significantly higher risk of depression, anxiety disorders and suicidal ideation in adulthood than not exposed adults. In addition to various other studies, Stapinski, Bower and colleagues (2014) conducted a longitudinal study initiated with children aged 13 years in England. The results indicated that children exposed to peer bullying at this age, compared to their non-bullied peers, have three times higher risk of developing anxiety disorders. In this respect, it will not be wrong to say that childhood bullying experience has negative effects on the people's adulthood life. It has been observed that studies conducted with twins also support the emergence of psychological problems as a result of peer bullying. It has been revealed that peer bullying does not only affect the individual psychologically in different periods of life but also cause to show physical symptoms as well. For example, bullying was associated with physical symptoms such as headache, stomachache, acne and dizziness as well as bad mood, nervous feeling, difficulty in sleeping, morning fatigue, loneliness, and despair (Due et al., 2005).

Conclusion: In consequence, it was revealed that being a victim, bully or victim / bully during school years affects the individual in many respects both during the exposure time and during the individual adulthood. Uneri (2011) noting the intensity of the young population in Turkey and points that peer bullying indicates more risks than other countries. In the light of this information, a detailed picture of this psychological situation faced by the young population and the creation of a "map of need" (based on prevention/intervention strategies) are found to be priorities for both individual and community mental health. Information on prevention programmes developed by different countries has also been reached and mentioned in the present study. The effectiveness of these prevention programmes used in various countries should be examined in detail urgently. To eliminate possible and also negative psychological consequences; cultural compatibility should be taken into consideration and wide-ranging policy of prevention and awareness should be put into force immediately. 


\section{Akran Zorbalığı}

Özellikle okul çağındaki çocuk ve gençler arasında gözlenen akran zorbalığı her geçen yıl artış gösteren bir olgu olarak karşımıza çıkmaktadır. Akran zorbalığına ilişkin vakalardaki bu artış uzmanların konuya olan ilgilerini de arttırmıştır. Olweus (1994: 98) zorbalığı zaman içinde tekrarlanan ve devam eden, bir veya daha fazla kişi üzerinde olumsuz sonuçları olan eylemler bütünü olarak tanımlamıştır. Pişkin (2002: 536) ise, okul zorbalığı olarak ele almış ve mağdurun kendisini koruyamadığı, bir ya da birden fazla güçlü öğrencinin daha güçsüz öğrencilere uyguladıkları sürekli ve kasıtlı rahatsız edici davranışlar olarak değerlendirilmiştir. Söz konusu tanımların yanı sıra akranlar arasında gerçekleşen bir saldırganlığın zorbalık olarak ele alınabilmesi için birtakım kriterleri karşılıyor olması gerekmektedir. Özellikle, davranışın bilinçli ve kasıtlı bir şekilde yapılması, bilinçli bir şekilde zarar verme amacı taşıması, davranış ya da davranışlar bütününün tekrarlayıcı olması, mağdur ile zorba arasında güç dengesizliğinin olması, mağdurun kendini koruyamaması, mağdurun hafif veya şiddetli travmaya maruz kalması, zorbanın çıkar sağlaması, zorbanın yapmış olduğu davranışından haz duyması bu temel kriterler arasından ilk olarak göze çarpanlardır (Çocuğa Yönelik Şiddetin Önlenmesi Projesi, 2015; Nazir ve Pişkin, 2015). Ancak söz konusu spesifik tanımlar ve konuya ilişkin akademik yaklaşımların öncesinde akran zorbalığı şiddet olgusunun bir parçasıdır; şiddettin farklı bir gösteriliş şeklidir. Diğer bir deyişle, akran zorbalığı, şiddet olgusunun birey ve toplum üzerinde yaratmakta olduğu bütün etki ve sonuçlarıyla ortak bir paydada buluşmaktadır.

Okul çağı dönemindeki çocuklar arasında sıklıkla karşılaşılan bu şiddet türünün farklı uygulama şekilleri vardır. ilgili uygulama şekilleri tartışılırken konuya müdahil olan çocuklar mağdur, zorba ya da hem mağdur hem de zorba (yani bir çocuğun bir tarafta zorbalık mağduru olurken bir yandan da başka çocuklar üzerinde zorbalık davranışı gösterebildiği durumlar) olarak konunun paydaşı olabildikleri ve akran zorbalığının bu üç grup üzerinde de dramatik sonuçları olduğu unutulmamalıdır. Mynard ve Joseph (2000), akran zorbalığı üzerine yapmış olduğu çalışmalar neticesinde, zorbalığın fiziksel mağduriyet, sözel mağduriyet, sosyal manipülasyon ve eşyaya zarar verme şeklinde sınıflandırılabilceğini belirtmiştir. Fiziksel mağduriyet olarak vurma, tekme atma, itme, tokat atma; sosyal manipülasyon olarak arkadaşlarıyla arasını bozma, arkadaşlarının ona karşı olmasına neden olma, oyunlara alınmasını engelleme, yalnız bırakılmasını sağlama; sözel mağduriyet olarak isim takma, görüntüsüyle dalga geçme, hakaret etme ve diğer bir noktada eşyaya zarar verme davranışı olarak izinsiz bir şeyini alma, kitaplarını çöpe atma, bir şeyini kırmayı deneme gibi davranış paternleri örnek verilmiştir (Mynard ve Joseph, 2000). Rigby'e göre (2003), vurma, tekme atma, birine saldırmak için başkalarını toplama, eşyalarını alma veya saklama en sık gözlenen zorbalık davranışlarıdır. Ayrıca, Mynard ve Joseph'ten (2000) farklı olarak Rigby (2003) sosyal manipülasyonu ilişkisel zorbalık olarak tanımlamıştır. Hawker ve Boulton (2000) ise biraz daha farklı bir yol izleyerek akran zorbalığını dolaylı mağduriyet, ilişkisel mağduriyet, fiziksel mağduriyet, sözel mağduriyet ve genel mağduriyet olmak üzere beşe ayrılabileceğinden bahsetmiştir. Belirtilen sınıflandırmaların yanı sıra zorbalık davranışı sözel ve sözel olmayan davranışlar olarak iki kategoride de ele alınabilmektedir (Rigby, 2003). Hakaret etme, haksız eleştiri, iğneleme, aşağılama, ad takma ve benzeri şekilde açıkça gözlemlenebilen sözel davranışların beraberinde tehdit edici veya müstehcen jestler (parmak işareti, dil çıkarma, göz devirme gibi), tehditkar bakışlar, kasıtlı olarak dönüp uzaklaşmak şeklinde gerçekleştirilen sözel olmayan ve beden dilinin kullanımına yönelik davranışlar da zorbalık olarak değerlendirilmektedir. Belirtilen zorbalık şekillerinin yanı sıra teknoloji kullanımının yaygınlığı neticesinde son yıllarda daha çok karşılaştığımız bir diğer zorbalık türü de siber zorbalıktır. Siber zorbalığın, geleneksel zorbalıktan farkı her hangi bir zamanda ortaya çıkabilmesi ve yayılma hızından kaynaklanmaktadır (Kowalski ve Limber, 2007). Teknoloji zorbaların mağdurlara yer ve zaman kısıtlaması olmaksızın zorbalık yapabilmesine olanak tanımaktadır (David-Ferdon ve Hertz, 2007; Ayas ve Horzum, 2010). Patchin ve Hinduja (2006) en basit haliyle siber zorbalığı rahatsız edici davranışları kasten ve tekrarlayıcı bir şekilde elektronik mecralar üzerinden sürdürmek olarak tanımlamışlar ve aslında siber zorbalığı, geleneksel zorbalı̆ın gerçek dünya yerine siber dünyaya kaydırılarak, cep telefonları ve bilgisayarlar üzerinden gerçekleşmesi olarak betimlemişlerdir. Bu durum, zorbalık uygulayanlara her an ulaşabilme imkanı sağlarken mağdurların da her an zorbalığa maruz kalabilmelerine neden olmakta; travmatik sonuçlarını diğer gruplara oranla daha yoğun yaşayabilmektedirler.

Akran zorbalığının görülme sıklıklarına yönelik yurtdışında yapılan çalışmaları incelediğimizde, okul çağı grubundaki çocukların mağdur ya da zorba veya hem mağdur hem de zorba olarak zorbalık davranışından etkilenme oranları \%4 (Jansen ve ark., 2012), \%17 (Jansen ve ark., 2012), \%20.8 (National Center for Education Statistics, 2016), \%26.1 (Han, Zhang ve Zhang, 2017) olarak karşımıza çıkmaktadır. Kültürlerarası yapılan çalışmalarda ise ülkeler bazında \%10-30 (Stapinski, Bower ve ark., 2014), \%1-50 (Dünya Sağlık Örgütü, 2004) değiştiği saptanmıştır. Zorbalık hakkında yapılan bir metaanaliz çalışmasında ise ortalama olarak öğrencilerin \%35'inin geleneksel (fiziksel, sözel), \%15'nin ise siber zorbalığa karıştıkları tespit edilmiştir (Modecki, Minchin, Harbaugh, Guerra ve Runions, 2014). 
Türkiye'de yapılan çalışmalarda siber zorbalık oranlarının \%47.6 (Topçu, 2018), \% 35.7 (Arıcak ve ark., 2008), \%9.42 (Serin, 2012) hem zorba hem mağdur oranlarının ise \%23.8 (Arıcak ve ark., 2008), \%5.31 (Serin, 2012), mağdur oranlarının ise \%5.9 (Arıcak ve ark., 2008), \%11.79 (Serin, 2012) olduğu görülmektedir. Geleneksel zorbalık açısından bakıldığında ise bazı çocukların, mağdur, zorba veya zorba/mağdur olarak \%35 (Pişkin, 2003), \%40 (Kapçı, 2004), \% 40.6 (Alikasifoğlu ve ark., 2007), \%17 (Özdinçer-Arslan, 2008), \%32.1 (Totan, 2008), \%25.1 (Totan ve Kabakçı, 2010), \%35.5 (Atik, Özmen ve Kemer, 2012) gibi yüksek oranlarda zorbalık döngüsünde yer aldıkları görülmüştür.

Ülkemizde ve yurtdışında yapılan çalışmalarda zorbalığın görülme sıklıklıklarını genel olarak göz önünde bulundurduğumuzda ise, oranların yüksek olduğu ve elde edilen verilerin her geçen yıl içerisinde artış gösterdiği dikkat çekmektedir. Ayrıca Üneri (2011) Türkiye'deki genç nüfusun yoğunluğuna dikkat çekerek zorbalığın diğer ülkelere oranla daha fazla risk oluşturduğuna işaret etmektedir.

\section{Travma Sonrası Stres Bozukluğu}

Travma, gerçek veya göz korkutan bir şekilde ölümle veya ağır yaralanmayla karşılaşma veya cinsel saldırıya uğrama şeklinde tanımlanmaktadır (American Psychiatric Association, 2013). Travmayı takip eden süreçte ise bireyler çeşitli zorlayıcı psikolojik belirtiler ile karşılaşabilmektedirler. Bunlardan bir tanesi olan travma sonrası stres bozukluğunun belirtileri temel olarak travmayı yeniden yaşama; kaçınma; travmatik olayın büyük bir kısmını hatırlayamama, unutkanlık, olumsuz inanç ve beklentiler içinde olma gibi bilişsel süreçte ve duygu durumundaki olumsuz değişimler; bedende aşırı enerji hissetme, sürekli tetikte olma vb. şeklinde gözlenen aşırı uyarılma (Amerikan Psikiyatri Birliği, 2014) olarak karşımıza çıkmaktadır.

Travma sonrası stres bozukluğunun en temel sonuçlarından olan travmayı yeniden yaşama ve kaçınma davranışları açısından detaylı değerlendirecek olursak, travmayı yeniden yaşama travmatik yaşantının kendisi olarak düşünülmese de rüyalarla ya da bazı tetikleyicilerle bireyin olayı bedenen ve zihnen tekrar yaşamasıdır. Kaçınma ise travmayı hatırlatan ipuçlarından uzaklaşmaktır. Birey, travmanın bu sonuçları karşısında anksiyete, aşırı tetikte olma, uyku bozukluğu, istenmeyen düşüncelerin zihne gelmesi, suçluluk, utanç, üzgünlük, öfke, geri çekilme, zihinsel olarak kaçınma, duygusal kaçınma gibi psikolojik tepkiler gösterebilmektedir (Regel ve Joseph, 2017).

Levin'e (2008) göre travma, insan acılarının; en çok kaçınılan, göz ardı edilen, reddedilen, yanlış anlaşılan ve tedavi edilmeyen yaşantılarının bir sonucudur. Travma denildiğinde yaşamı tehdit edici olarak algılanan olaylardan veya yıkıcı yaşantılardan sonra insanlara acı veren, çoğunlukla onları zayıf duruma düşüren olaylar söz konusu olmaktadır. Bunun beraberinde, bütün travmatik olaylar stres verici olsa da stres veren tüm olaylar travma olarak adlandırılamamaktadır.

Kişinin travmatize olmasına ve travma tepkilerinin ortaya çıkmasına neden olacak yaşantıların "felaket" olması şart değildir. Tekrarlayıı bir şekilde gerçekleşen "küçük" bir olay ya da olaylar serisi de travmaya neden olabilmektedir. Bunun beraberinde, Lancaster, Melka ve Rodrigez, (2009) bunlara ek olarak; kişilerarası olumsuz deneyimleri olan kişilerin diğer olumsuz olayları (doğal afet, yangın gibi) yaşayan kişilere göre daha yüksek düzeyde travmatize olduğu ve travma sonrası stres bozukluğu semptomları gösterdiğini belirtmişlerdir.

Travma sonrası stres bozukluğu ile ilgili çalışmalar incelendiğinde, konuya ilişkin yapılan ilk araştırmalarda çocuklarla çalışılmadığı görülmüştür (Dyregrov ve Yule, 2006). Söz konusu bu çalışmalarda travma sonrası stres bozukluğu bir felaketten sonra yaygın olarak görülen semptomlar yelpazesini tanımlamak ve açıklamak için kullanılmıştır (Weaver, 2000). Toplumsal bir mit olarak çocukların yaşlarından ötürü düşünce yapılarının daha esnek olduğu ve travmatik olayları daha kolay unutabildikleri ya da bu olaylardan etkilenmedikleri yönündeki inancın da (Gökler Danışman ve Okay, 2017) travmaya ilişkin çalışmalarda çocuklara yer verilmeme nedenlerinden biri olduğu düşünülmektedir. Ancak, travma üzerine yapılan çalışmaların artışı çocuklarla yürütülen araştırmaları da desteklemiş ve zamanla bu hedef gruba olan ilgi artmıştır. Akran zorbalığının bir şiddet türü olarak görülmeye başlanması ve birey üzerindeki etkilerinin saptanmasıyla neticesinde ise travma çalışmaları okullardaki yerlerini almıştır. Özellikle, son yıllardaki gözlenme sıklıklarındaki artışa bakıldığında akran zorbalığının travma sonrası stres bozukluğu semptomlarının ortaya çıkısına ilişkin önemli bir risk etmen olduğu kanısına varılmış ve bu alandaki çalışmalar arttırılmıştır.

\section{Yöntem}

Bu çalışma sistematik literatür taraması yoluyla yapılmıştır. Akran zorbalığı ve akran zorbalığına bağlı ortaya çıkan travmatik sonuçlar arasındaki ilişkinin ele alındığı bu derleme çalışmasında konuya ilişkin ampirik çalışmaların incelenmesi amaçlanmıştır. 
Derleme çalışmasında yer verilecek çalışmalar için belirlenen kriterler şu şekilde belirlenmiştir: (1) çalışmanın hakemli bir dergide yayınlanmış orjinal araştırma makalesi ya da derleme çalışması; (2) çocukluk ya da ergenlik döneminde akran zorbalığına maruz kalma ile zorbalık temelli bir ya da birden fazla travmatik sonuçla ilişkili verilerin ele alınmış olması; (3) akran zorbalı̆̆ına maruz kalma ile yetişkinlik döneminde gözlemlenen travma sonrası belirtiler arasındaki ilişkiyi açıklıyor olması; (4) popülasyon temelli bir çalışması olması.

Alan taraması yapılırken PsycINFO, ERIC, ScienceDirect ve PubMed benzeri kaynaklardan yararlanılmıştır. Söz konusu çalışmanın amacı kapsamında Türkçe dilinde çocuk ve ergenlere yönelik yapılmış çalışmalara rastlanmadığından arama yabancı alanyazın ile sınırlandırılmış ve İngilizce dilinde yapılmıştır. Tarama sürecinde "bullying", "bullied", "peer victimization", "harassment", "trauma", "post traumatic stress symptoms", "stresfull life event" anahtar kelimeleriyle birlikte "child" ve "adolescent" anahtar kelimleri kullanılmıştır. Diğer düzeyde başlıklar için metin kalın kullanılabilir. Sayılar kullanılmamalıdır.

\section{Bulgular}

Akran zorbalığına ilişkin araştırmalar ilk olarak 1960lı yıllarda ortaya çıkmıştır (Berger, 2007). Buna karşılık konuya ilişkin ilk sistematik çalışmalar, Norveç'te akranları tarafından zorbalığa uğradığını ifade eden notlar bıraktıktan sonra kendini öldüren üç öğrenci sonrasında başlamıştır (Berger, 2007). Bu olay sonrasında, akran zorbalığına maruz kalan kişilerin zorbalık sonrasında yaşamış oldukları psikolojik sıkıntılara dair birçok çalışma yapılmaya başlanmıştır. Araştırmalar, sağlık problemlerine, davranışsal ve duygusal problemlere, depresyona, psikotik semptomlara ve düşük okul başarısına yoğunlaşmıştır (Brendgen ve Poulin, 2018; Copeland ve ark., 2013; Eastman ve ark., 2018; Lee ve Vaillancourt, 2018). Ayrıca, akran zorbalığında kişinin zorba ya da mağdur olduğuna bakılmaksızın intihar düşüncesi ve intihar girişimi oranlarında da artış olduğunu ifade eden çalışmalar gerçekleştirilmiştir (Kim ve Leventhan, 2008, Klomek, Sourander ve Gould, 2010).

Akran zorbalığı mağduru olma ve içsel semptomlar arasındaki ilişkinin incelendiği çalışmalar anksiyete (Brendgen ve Poulin, 2018; Eastman ve ark. 2018; Lee ve Vaillancourt, 2018) ve anksiyeteye bağlı olarak duygudurum bozukluklarındaki artışa, düşük özgüven seviyesine, sosyal içe çekilmeye, yalnızlığa ve tutum değişikliklerine neden olan stres tepkilerine (Hamilton, Newman, Delville ve Delville, 2008; Tsaousis, 2016); uyku bozukluklarına (van Geel ve ark, 2016) ve psikotik semptomlara (Arseneault, Bowes ve Shakoor, 2010; van Dam ve ark, 2012) dikkat çekmiştir. Araştırmalarca ele alınan bütün bu içsel semptomların travma sonrası stres bozukluğu belirtilerine işaret ettiği açıkça görülmektedir. Mağdur olma ile dışsal semptomlar arasındaki ilişkiye yönelik olarak suça yönelmede artış, bağımlılık yapıcı madde kullanımı ve davranış bozukluklarından bahsedilmiştir (Eastman ve ark, 2018; Kretschmer ve ark, 2018; Quinn ve Stewart, 2018). Shakoor ve arkadaşları (2015) yapmış oldukları çalışma neticesinde zorbalık ile paranoya arasındaki ilişkiye dikkat çekmişlerdir. Akranları tarafından zorbalığa maruz kalan ergenlere yapılan çalışmalar ise zorbalığın depresyon, intihar düşüncesi ve intihara kalkışma noktasında risk oluşturduğunu göstermektedir (Baldry ve Winkel, 2003; Brunstein Klomek Marrocco, Kleinman, Schonfeld ve Gould, 2008; Castellví ve ark. 2017; Holt ve ark., 2015; Van Geel ve ark., 2014). 28 ülkedeki ergenler üzerinde yapılan uluslararası bir çalışmada zorbalığın hem fiziksel hem de psikolojik sorunlara zemin oluşturduğunun açıkça altı çizilmiştir (Due ve ark., 2005). Zorbalığın baş ağrısı, mide ağrısı, akne, baş dönmesi gibi fiziksel semptomlarla ve kötü ruh hali, sinirli hissetme, uyumakta güçlük çekme, sabah yorgunluğu, yalnızlık, çaresizlik gibi psikolojik semptomlarla ilişkili olduğu görülmüştür (Due ve ark., 2005).

Literatürde karşılaşılan bir grup çalışmada akran zorbalı̆̆ının uzun vadede travmatik semptomlara yol açtığı bilgisinin üzerinde durulmaktadır (Arseneault, Bowes ve Shakoor, 2010; Baldry ve Winkel, 2003). Stapinski, Bower ve arkadaşları (2014) tarafından İngiltere' de 13 yaş grubu çocuklarla başlatılan boylamsal bir çalışmada bu yaş grubunda zorbalık mağduru olan çocuklarda ileriki yaşlarda zorbalık mağduriyeti olmayan çocuklara oranla anksiyete bozukluklarının görülme sıklığııın üç kat fazla olduğu tespit edilmiştir. Patalay ve Fitzsions (2017), 14 yaş grubu öğrencileriyle yaptıkları bir çalışmada ise, benzer sonuçlara dikkat çekmiş ve özellikle her dört kız öğrenciden birinin depresif semptomlar sergilediğini ifade etmişlerdir.

İntihar düşüncesi ve intihar girişimi, sosyal anksiyete, sosyal ortamlardan uzak durma şeklinde gözlenen (Silberg, Copeland, Linker ve Moore, 2016) "kaçınma” davranışlarıyla; depresyon, halüsinasyon görme, sosyal ortamlarda aşırı uyarılmışlık hali, aşırı tetikte olma, uyku bozukluğu (Nielsen, Tangen, Idsoe, Matthiesen ve Magerøy, 2015, Silberg, Copeland, Linker ve Moore, 2016; Weaver, 2000,) şeklinde ortaya çıkan diğer travmatik semptomlarla da karşılaşılabilmektedir. Söz konusu tablo, akran zorbalığına maruz kalma ile ilerleyen dönemlerde gözlenen travma sonrası stres bozukluğu belirtileri arasındaki ilişkiye ve önleme çalışmalarının önemine işaret etmektedir. 
Çocukluk döneminde maruz kalınan zorbalık ile ileriki yaşlarda gözlemlenen travmatik semptomlar arasındaki ilişkiye ilişkin en çarpıcı çalışmalardan bir diğeri de Silberg ve arkadaşları (2016) tarafından gerçekleştirilmiştir. Silberg ve arkadaşları yapmış oldukları araştırmada 145 tek yumurta ikiziyle çalışmıştır ve psikolojik problemlerin görülme oranları açısından çocukluk döneminde zorbalığa maruz kalan ikizler ile maruz kalmayan ikizlerden elde edilen verileri karşılaştırmışlardır. Boylamsal analizler neticesinde elde edilen sonuçlara göre çocukluk döneminde zorbalıktan mağdur olan ikizlerde mağdur olmayan ikizlerine oranla sosyal anksiyetenin (1.7), bağlanma anksiyetesinin (1.9) ve intihar düşüncesinin (1.3) daha fazla gözlendiği saptanmıştır (Silberg, Copeland, Linker ve Moore, 2016). İkizlerle yapılan bir diğer araştırmada da aileleri ve öğretmenleriyle yapılan görüşmeler neticesinde zorbalığa uğradığı tespit edilen 7-10 yaş grubundaki ikiz kardeşlerle çalışılmıştır. Araştırma neticesinde zorbalığa uğrayan çocukta zorbalığa uğramayan ikizine oranla psikolojik problemlerin gözlenme oranının daha fazla olduğuna dikkat çekilmiştir (Arseneault ve ark., 2008).

Ingiltere'de yapılan geniş kapsamlı başka bir çalışmada ise, aileleriyle yapılan görüşme neticesinde 7-11 yaş aralığındayken akran zorbalığına uğradığı belirtilen 7771 katılımcı araştırmaya dahil edilmiştir. Yapılan çalışmada katılımcıların 23 ile 50 yaş aralığında karşılaştıkları psikolojik problemlere bakılmıştır. Çalışma sonucunda, 7-11 yaşlarında zorbalığa maruz kalan çocukların zorbalığa maruz kalmayan çocuklara oranla yetişkinlik dönemlerinde depresyonla, anksiyete bozukluklarıyla ve intihar düşüncesiyle karşı karşıya kalma riski önemli derecede yüksek bulunmuştur (Takizawa, Maughan ve Arseneault, 2014).

Finladiya'da School Health Promotion Study kapsamında 14-16 yaş grubunda öğrencilerle yapılan bir çalışmada akran zorbalığı ve mağduriyeti ile depresyon, anksiyete, yeme bozuklukları vb. travmatik semptomlar arasındaki ilişki ele alınmıştır. Çalışmada kız öğrencilerin \%9'unun ve erkek öğrencilerin \%17'sinin akran zorbalığına maruz kaldığı; mağdur öğrencilerin anksiyete ve depresyon semptomlarının yanı sıra travmatik belirtileri de sergiledikleri sonucuna varılmıştır. (Riittakerttu ve ark. 2000). Finlandiya'da yapılan diğer bir çalışmada ise çocukluk döneminde zorbalığa maruz kalan kişilerin yetişkinlik döneminde şiddetli depresif semptomlar gözlendiği ve intihar girişim oranlarının arttığının altı çizilmiştir (Klomek ve ark., 2009).

Idsoe ve arkadaşları (2012) tarafından 963 çocukla yapılan çalışmada zorbalığa maruz kalma oranlarının erkeklerde kızlara göre 2.27 kat daha fazla olduğu bulunmuştur. Ancak çalışmanın önemli bir boyutu, zorbalığa maruz kalan çocuklardan erkeklerin \%27.6'sının ve kızların \%40.5'inin travma sonrası stres bozukluğu semptomlarına sahip olduğuna işaret etmektedir (Idsoe ve ark., 2012). ilgili çalışmanın bir diğer dikkat çekici sonucu ise, zorbalık uygulayan ve zorbalığa maruz kalan grubun sadece zorbalığa maruz kalan gruba göre daha klinik bir tablo sergilediği yönündedir. Bu sonuçla tutarlı olarak Carney (2008) de mağdur, zorba veya zorba/mağdur rolüne bakılmaksızın herkesin üzerinde zorbalığın travmatik etkisi olduğu sonucuna ulaşmıştır.

853 üniversite öğrencisi üzerinde yapılan başka bir araştırmada ise, lise ve lise öncesinde maruz kalınan zorbalık ile travma sonrası stres belirtileri arasındaki ilişki incelenmiştir. Çalışmanın sonucuna göre lise döneminde zorbalığa maruz kalma ile travma ve stres belirtileri arasında ilişki bulunmuş ve özellikle izolasyonun aracı bir etkisinin olduğu saptanmıştır (Newman, Holden ve Delville, 2005). Yapılan alanyazın taraması neticesinde görülmektedir ki, akran zorbalığında mağdur ya da zorba olma ile travma sonrası stres belirtilerinin gözlenme sıklıkları arasında belirgin bir ilişki bulunmaktadır (Mynarda, Josephb ve Alexander, 2000; Crosby, Oehler ve Capaccioli, 2010; Penning, Bhagwanjee ve Govender, 2010; Guzzo, Pace, Lo Cascio, Craparo ve Schimmenti, 2014; Nielsen, Tangen ve ark., 2015; Catone ve ark., 2015). Bu bağlamda, araştırmalarca belirtilmiş olan akran zorbalığına maruz kalma oranlarını da göz önünde bulundurursak travma sonrası stres bozukluğu belirtileri gösteren mağdur ve zorbaların oranının azımsanamayacağı görülmektedir.

\section{Tartışma ve Sonuç}

Akran zorbalığı dünyada ve ülkemizde okula devam eden çocuk ve ergenler arasında her geçen yıl artış gösteren bir olgu olarak karşımıza çıkmaktadır. Son yıllarda akran zorbalığına ilişkin davranışların sıklığında gözlenen artış uzmanların da dikkatini çekmiş; bu sayede zorbalık davranışının hem zorbalığı uygulayan hem de zorbalığa maruz kalan taraflar açısından etkilerinin saptanmasına yönelik çalışmaların sayısı artmıştır. Yapılan çalışmalardan elde edilen veriler neticesinde uzmanlar zorbalık olgusundan hem mağdur hem zorba olmak üzere her iki grubun da zarar gördüğüne dikkat çekmişlerdir. Ancak, mağdur olan kişilerin yaşamakta olduğu uzun dönemli problemlerin depresyon, anksiyete ile sınırlı kalmadığı travma sonrası stres bozukluğu çerçevesinde değerlendirilebilecek çoklu semptomlar sergiledikleri ve ihtiyaç duyulan desteğin sağlanamadığı hususlarda intihara kadar gidebildiğinin altı çizilmiştir. Öyle ki, yetişkinlik döneminde bile iş yerinde zorbalığa maruz kalmanın yüksek düzeyde travma sonrası stres bozukluğu belirtileri ile ilişkili olduğu görülürken (Tehrani, 2004) benlik kavramını oturtma aşamasında olan, 
kimlik karmaşası içinde olan okul grubu bireylerinin söz konusu semptomları daha ağır ve daha kalıcı bir şekilde yaşadığı alanyazında ele alınan çalışmalar tarafından dikkat çekilmiştir. Yetişkinlikte yaşanan bir travma kişiliği aşındııırken, çocuklukta yaşanan travmanın çocuğun kişiliğini olumsuz yönde etkilediğinin ve bu etkinin farklı belirtilerle uzun yıllar boyunca bireyi rahatsız ettiğinin altı çizilmektedir (Herman, 2015).

Bu bağlamda, gerçekleştirilen alanyazın incelemesi sonucunda, travma söz konusu olduğunda insan eliyle gerçekleştirilen olayların daha fazla olumsuz sonuçlara sebebiyet verdiği (Lancaster, Melka ve Rodrigez, 2009) ve travma sonrası stres belirtilerine neden olduğu da göz önünde bulundurularak akran zorbalığının sadece okullar, öğretmenler ya da annebabalar tarafından değil toplumun bütün bileşenleri tarafından ele alınması gereken bir konu olduğu sonucuna varılmıştır. Özellikle çocukluk ve ergenlik dönemlerinde sıkça karşılaştığımız bir olgu olduğu göz önünde bulundurulduğunda, toplum tarafından kabulü sağlanmış, geniş kapsamlı ve tutarlı önleme çalışmalarının gereksinimi bir kat daha artmaktadır.

Diğer bir bakış açısıyla, zorbalığın etkilerinin yıllar sonra da devam etmekte olduğu, ancak bu devamlıığın herkes için aynı derecede olmadığı, ağırlıklı olarak izole hisseden bireylerde varlığını sürdürdüğü görülmektedir (Newman, Holden ve Delville, 2005). Özellikle, zorbalığa maruz kalan çocukların çoğunlukla bu durumu yetişkinlere bildirmemesi, tek başlarına baş etmeye çalışmaları (Hicks, Jennings, Berry ve Green, 2018), zorbalık mağduru olan çocukların sosyal destekten mahrum bir şekilde sorunla baş etmek zorunda kaldıklarını bize göstermektedir. Bu doğrultuda bahsi geçen izolasyon sürecinin çocukluk çağında daha büyük bir risk olarak karşımıza çıkmakta olduğu görülmektedir. Çocuklar yaşamakta oldukları travmatik süreç karşısında yalnız hareket etmekte ve zorbalığın olumsuz etkilerinden daha fazla etkilenmektedirler. Detay olarak belirtilebilecek bu durum dahi zorbalığın önlenmesine ilişkin farkındalık çalışmalarının, kampanyalarının önemini vurgulamaktadır.

Söz konusu çalışmalara örnek olarak Finlandiya'da 3-6, 6-12 ve 13-16 yaş grupları için farklı içeriklerle uygulanan KiVa önleme programının zorbalık ve zorbalık sonucu karşılaşılan problemlerin azaltılmasında yaklaşık \%60 oranında destek sağladığı sonucuna varılmıştır (Kärnä ve ark., 2011). Benzer şekilde Avustralya'da çocuk ve ailelerine yönelik uygulanan Resilience Triple $\mathrm{P}$ programı zorbalığa maruz kalan çocukların psikolojik dirençlerini arttırmak ve zarar görme oranlarını azaltmak adına olumlu sonuçlar vermiştir (Healy \& Sanders, 2014). ilkokul, ortaokul ve lise grubu öğrencilerine yönelik olarak hazırlanmış olan Olweus Bullying Prevention Program (OBPP) adlı önleme programının Norveç'te dört yıl boyunca gerçekleştirilen uygulamaları sonucunda okul kültürünün oluşturulabildiği ve zorbalığın uzun dönem etkilerinde azalmaların gözlendiği sonucuna varılmıştır (Olweus, Solberg ve Breivik, 2018). Avusturalya'da geliştirilen ve 8-12 yaş grubu öğrencilerine uygulanan Steps to Respect önleme programının OBPP'ye benzer şekilde olumlu okul ikliminin oluşturulmasında ve zorbalığın kısa ve uzun dönem etkilerinin azaltılmasında etkili olduğu görülmüştür (Frey ve ark, 2005). İtalya'da 14-18 yaş grubu ergenlere uygulanan NoTrap! ("Not fall into the trap" sloganının kısaltmasıdır) önleme programı genel zorbalık ve siber zorbalık sorunları karşısında diğer programlarla benzer şekilde olumlu sonuçlar almıştır (Palladino, Nocentini ve Menesini, 2016). İngiltere'de hemen hemen bütün üniversiteler ve sivil toplum kuruluşları, okullar tarafından sahip çıkılan AntiBullying Week farkındalık haftasında 2018 yılında "Choose Respect" sloganıyla ve "\#StopSpeakSupport" etiketiyle hem öğrencilerin hem eğitimcilerin hem de toplumun dikkatinin çekilmesi amaçlanmıştır. Bunların beraberinde Tabby Trip in Europe, Addressing Sexual Bullying across Europe (ABSAE), Mi Voglio Bene (MVB), Su la Tessta, Generazioni Connesse - Safer Internet Center (SIC), Bulli di Sapone zorbalığa karşılık geliştirilen önleme programlarından sadece birkaçıdır.

Sonuç olarak, konuya ilişkin alanyazında yer alan araştırmaların incelenmesi neticesinde, akran zorbalığına ilişkin ivedilikle ele alınması gereken hususların bulunduğu sonucuna varılmıştır. Öncelikle akran zorbalığına ilişkin yapılmış araştırmalar ve önemli gelişmelere karşılık ülkemizdeki çocuk ve gençlerin maruz kaldığı zorbalığa bağlı yaşamakta oldukları psikolojik tabloya karşın net bir önleme ve çözüm politikasının bulunmadığı dikkat çekmektedir. Bu noktada, genç nüfusun karşı karşıya kaldığı bu psikolojik tablonun detaylı bir şekilde oluşturulması ve bir ihtiyaç (önleme/müdahale) haritasının oluşturulması hem birey hem de toplum ruh sağlığı açısından öncelikli görülmektedir. Ayrıca, ülkemizdeki önleme faaliyetlerinin düzenlenmesi, ülke genelinde uygulanabilir önleyici/koruyucu politikalar geliştirilmesi açısından mevcut çalışmada da yer alan, diğer ülkelerde uygulanmakta olan programların sistematik olarak gözden geçirilmesi ve bu önleme programlarını etkili kılan temel bileşenlerinin neler olduğunun belirlenmesinin önemli olduğu düşünülmektedir. Bu çalışmalar neticesinde, ihtiyaç haritası ve başarılı çalışmaların temel bileşenlerinin uygun zeminde bir araya geitirilmesi ile önleme ve farkındalık programları ortaya konarak, artarak gözle görülür hale gelen akran zorbalığına ve olası olumsuz sonuçlarına karşı çözüm geliştirilmesi doğrultusunda önemli adımların atılacağına inanılmaktadır. 


\section{References}

Alikaşifoglu, M., Erginoz, E., Ercan, O., Uysal, O. ve Albayrak-Kaymak, D. (2007). Bullying behaviours and psychosocial health: Results from a cross-sectional survey among high school students in İstanbul, Turkey. Eur J Pediatr, $166,1253-1260$.

American Psychiatric Association. (2013). Diagnostic and statistical manual of mental disorders (5th ed.). Arlington, VA: Author.

Amerikan Psikiyatri Birliği (2014). Ruhsal bozuklukların tanısal ve sayımsal el kitabı (DSM-V) (5. Baskı). Tanı Ölçütleri Başvuru Kitabı'ndan, (Köroğlu, Çev.). Ankara: Hekimler Yayın Birliği.

Arıcak, T., Siyahhan, S., Uzunhasanoğlu, A., Saribeyoğlu, S., Çıplak, S., Yılmaz, N. \& Memmedov, C. (2008). Cyberbullying among Turkish adolescents. CyberPsychology \& Behavior, 11(3), 253-261.

Arseneault, L., Milne, B.J., Taylor, A., Adams, F., Delgado, K., Caspi, A. \& Moffitt, T.E. (2008). Being bullied as an environmental-ly mediated contributing factor to children's internalizing problems. Arch Pediatr Adolesc Med., 162(2), 145-150. doi:10.1001/archpediatrics.2007.53

Arseneault, L., Bowes, L. \& Shakoor, S. (2010). Bullying victimization in youths and mental health problems: "Much ado about nothing?". Psychological Medicine, 40(5), 717-729. doi:10.1017/\$0033291709991383.

Atik, G., Özmen, O. ve Kemer, G. (2012). Zorbalık ve boyun eğme davranışı. Ankara Üniversitesi Eğitim Bilimleri Fakültesi Dergisi, 45(1), 191-208.

Ayas, T. ve Horzum, M. B. (2010). Sanal zorba/kurban ölçek geliştirme çalışması. Akademik Bakış, 19, 1-17.

Bandura, A. (1977). Self-efficacy: Toward a unifying theory of behavioral change. Psychological Review, 84(2), 191215.

Baldry, A.C. \& Winkel, F. W. (2003). Direct and vicarious victimization at school and at home as risk factors for suicidal cognition among Italian adolescents. Journal of Adolescence, 26(6), 703-716. doi:10.1016/j.adolescence.2003.07.002

Berger, S. K. (2007). Update on bullying at school: Science forgotten? Dev Rev., 27(1), 90-126. doi:10.1016/j.dr.2006.08.002.

Brendgen, M. \& Poulin, F. (2018). Continued bullying victimization from childhood to young adulthood: A longitudinal study of mediating and protective Factors. Journal of Abnormal Child Psychology, 46, 27-39. doi:10.1007/s10802-017-0314-5

Brunstein Klomek, Marrocco, A.F., Kleinman, M., Schonfeld, I.S. \& Gould, M. S. (2008). Peer Victimization, Depression, and Sui-cidiality in Adolescents. Suicide and Life-Threatening Behavior, 38(2), 166-180.

Carney, J. V. (2008). Perceptions of bullying and associated trauma during adolescence. Professional School Counseling, 11(3), $2156759 \times 0801100304$.

Castellví, P., Miranda-Mendizábal, A., Parés-Badell, O., Almenara, J., et al. (2017). Exposure to violence, a risk for suicide in youths and young adults. A meta-analysis of longitudinal studies. Acta Psychiatrica Scandinavica, 135, 195-211. doi:10.1111/acps.12679

Catone, G., Marwaha, S., Kuipers, E., Lennox, B., Freeman, D., Bebbington, P. \& Broome, M. (2015). Bullying victimisation and risk of psychotic phenomena: Analyses of British national survey data. The Lancent Psychiatry, 2(7), 618-624. doi:10.1016/S2215-0366(15)00055-3

Copeland, W. E., Wolke, D., Angold, A. \& Costello, E.J. (2013). Adult psychiatric outcomes of bullying and being bullied by peers in childhood and adolescence. JAMA Psychiatry, 70(4), 419-426. doi:10.1001/jamapsychiatry.2013.504.

Crosby, J. W., Oehler, J. \& Capaccioli, K. (2010). The relationship between peer victimization and post-traumatic stress symptomatol-ogy in a rural sample. Psychology in the Schools, 47(3), 297-310. doi:10.1002/pits.20471.

Çocuğa Yönelik Şiddetin Önlenmesi Projesi (2015). Çocuğa yönelik şiddetin önlenmesi teknik destek projesi revize erken uyarı uygulamaları kitapçı̆̆ı. Ankara: Avrupa Birliği-Milli Eğitim Bakanlığı. 
David-Ferdon, C. and Hertz, M. F. (2007). Electronic media, violence, and adolescents: An emerging public health problem. Journal of Adolescent Health, 41(6), S1-S5. doi:10.1016/j.jadohealth.2007.08.020

Due, P., Holstein, B.E., Lynch, J., Diderichsen, F., Gabhain, S.N., Scheidt, P., Currie, C. \& The Health Behaviour in School-Aged Children Bullying Working Group (2005). Bullying and symptoms among school-aged children: International comparative cross-sectional study in 28 countries. European Journal of Public Health, 15(2), 128-132. doi: 10.1093/eurpub/cki105.

Dyregrov, A. \& Yule, W. (2006). A review of PTSD in children. Child and Adolescent Mental Health, 11, 176-184. doi:10.1111/j.1475-3588.2005.00384.x.

Eastman, M., Foshee, V., Ennett, S., Sotres-Alvarez, D., Reyes, H. L. M., Faris, R. \& North, K. (2018). Profiles of internalizing and externalizing symptoms associated with bullying victimization. Journal of Adolescence, 65, 101-110. doi:10.1016/j.adolescence.2018.03.007

Frey, K. S., Hirschstein, M. K., Snell, J. L., Van Schoiack-Edstrom, L., MacKensie, E. P. \& Broderick, C. J. (2005). Reducing play-ground bullying and supporting beliefs: An experimental trial of the Steps to Respect program. Developmental Psychology, 41, 479-491.

Gökler Danışman, I. ve Okay, D. (2017). Afetlerin çocuklar ve ergenler üzerindeki etkileri ve müdahale yaklaşımları. Türkiye Klinikleri J Psychol-Special Topic, 2(3), 189-197.

Guzzo, G., Pace, U., Lo Cascio, V., Craparo, A. \& Schimmenti, A. (2014). Bullying victimization, post-traumatic symptoms, and the mediating role of alexithymia. Child Indicators Research,7, 141. doi:10.1007/s12187013-9206-6.

Hamilton, L. D., Newman, M. L., Delville, C. L. \& Delville, Y. (2008). Physiological stress response of young adults exposed to bullying during adolescence. Physiology \& Behavior, 95, 617-624. doi:10.1016/j.physbeh.2008.09.001

Han, Z., Zhang, G. \& Zhang, H. (2017). School bullying in urban China: Prevalence and correlation with school climate. International Journal of Environmental Research and Public Health, 14(10), 1116.

Hawker, D. S. \& Boulton, M. J. (2000). Twenty years' research on peer victimization and psychosocial maladjustment: A meta-analytic review of cross-sectional studies. The Journal of Child Psychology and Psychiatry and Allied Disciplines, 41(4), 441-455.

Healy, K. L. \& Sanders, M. R. (2014). Randomized controlled trial of a family intervention for children bullied by peers. Behavior Therapy, 45, 760-777. doi:10.1016/j.beth.2014.06.001

Herman, J. (2015). Travma ve iyileşme şiddetin sonuçları ev içi istismardan siyasi teröre. (T. Tosun, Çev.,). (3. Basım). İstanbul: Literatür yayınları.

Hicks, J., Jennings, L., Jennings, S., Berry, S. \& Green, D.A. (2018). Middle school bullying: Student reported perceptions and prevalence. Journal of Child and Adolescent Counseling, 1-14. doi:10.1080/23727810.2017.1422645

Holt, M.K., Vivolo-Kantor, A.M., Polanin, J.R., Holland, K.M., DeGue, S., Matjasko, J.L. \& Reid, G. (2015). Bullying and suicidal ideation and behaviors: A meta-analysis. Pediatrics, 135, 496-509. doi:10.1542/peds.2014-1864

Idsoe, T., Dyregrov, A. \& Idsoe, E.C. (2012). Bullying and PTSD symptoms. J-Abnorm Child Psychol, 40(6), 901-11. doi: 10.1007/s10802-012-9620-0.

Jansen, P. W., Verlinden, M., Dommisse-van Berkel, A., Mieloo, C., Van der Ende, J., Veenstra, R. \& Tiemeier, H. (2012). Preva-lence of bullying and victimization among children in early elementary school: Do family and school neighbourhood socioeconomic status matter?. BMC Public Health, 12(1), 494.

Kapçı, E. G. (2004). İlköğretim öğrencilerinin zorbalığa maruz kalma türünün ve sıklığının depresyon, kaygı ve benlik saygısıyla ilişkisi. Ankara Üniversitesi Eğitim Bilimleri Fakültesi Dergisi 37(1):1-13.

Kärnä, A., Voeten, M., Little, T. D., Poskiparta, E., Kaljonen, A. \& Salmivalli, C. (2011). A large-scale evaluation of the KiVa antibullying program: Grades 4-6. Child Development, 82, 311-330. doi:10.1111/j.14678624.2010.01557.x

Kim, Y. S. \& Leventhal, B. (2008). Bullying and suicide: A review. Int J Adolesc Med Health., 20(2), 133-154. 
Klomek, A. B., Sourander, A. \& Gould, M. S. (2010). The association of suicide and bullying in childhood to young adulthood: a review of cross-sectional and longitudinal research findings. Can J Psychiatry, 55(5), 282-288.

Klomek, A. B., Sourander, A. \& Gould, M. S. (2010). The association of suicide and bullying in childhood to young adulthood: A review of cross-sectional and longitudinal research findings. Can J Psychiatry, 55(5), 282288.

Kowalski, R. M. \& Limber, S. P. (2007). Electronic Bullying among middle school students. Journal of Adolescent Health, 41, S22-S30. Doi:10.1016/j.jadohealth.2007.08.017

Kretschmer, T., Veenstra, R., Branje, S., Reijneveld, S.A., Meeus, W.H.J., Deković, M. \& Oldehinkel, A.J. (2018). How competent are adolescent bullying perpetrators and victims in mastering normative developmental tasks in early adulthood? Journal of Abnormal Child Psychology, 46, 41-56. doi:10.1007/s10802-017-0316-3

Lancaster, S. L., Melka, S. E. \& Rodriguez, B. F. (2009). An examination of the differential effects of the experience of DSM-IV defined traumatic events and life stressors. Journal of Anxiety Disorders, 23, 711-717. doi:10.1016/j.janxdis.2009.02.010.

Lee, K.S. \& Vaillancourt, T. (2018). Longitudinal associations among bullying by peers, disordered eating behavior, and symptoms of depression during adolescence. Journal of the American Medical Association Psychiatry, 75, 605-612. doi:10.1001/jamapsychiatry.2018.0284

Levine, P. (2005). Healing trauma. Boulder, CO: Sounds True Books.

Modecki, K.L., Minchin, J., Harbaugh, A.G., Guerra, N.G. \& Runions, K. C. (2014). Bullying prevalence across contexts: A meta-analysis measuring cyber and traditional bullying. Journal of Adolescent Health, 55(5), 602-611.

Mynard, H., Joseph, S. \& Alexander, J. (2000). Peer-victimisation and posttraumatic stress in adolescents. Personality and Individual Differences, 29(5), 815-821. doi:10.1016/s0191-8869(99)00234-2.

Mynard, H. \& Joseph, S. (2000). Development of the multidimensional peer-victimization scale. Aggressive behavior, 26(2), 169-178.

National Center for Education Statistics (2016). Student Reports of Bullying: Results From the 2015 School Crime Supplement to the National Crime Victimization Survey. https://nces.ed.gov/pubsearch/pubsinfo.asp?pubid=2017015 adresinden 2 Aralık 2018 tarihinde erişilmiştir.

Nazir, T. \& Piskin, M. (2015). School bullying: Effecting childs mental health. The International Journal of Indian Psychology, 2(4), 130-135.

Newman, M. L., Holden, G. W. \& Delville, Y. (2005). Isolation and the stress of being bullied. Journal of Adolescence, 28(3), 343-357. doi:10.1016/j.adolescence.2004.08.002

Nielsen, M. B., Tangen, T., Idsoe, T., Matthiesen, S. B. \& Mageroy, N. (2015). Post-traumatic stress disorder as a consequence of bullying at work and at school: A literature review and meta-analysis. Aggression and Violent Behavior, 21, 17-24. doi:10.1016/j.avb.2015.01.001

Olweus, D. (1994) Bullying at School. In L.R. Huesmann (Ed.) Aggressive Behavior: The Plenum Series in Social/Clinical Psychology. Boston: Springer.

Olweus, D., Solberg, M.A. \& Breivik, K. (2018). Long-term school-level effects of the Olweus Bullying Prevention Program (OBPP). Scandinavian Journal of Psychology, doi: 10.1111/sjop.12486.

Özdinçer-Arslan, S. (2008). Lise öğrencilerinde öz-kavram ve aile ilişkisinin akran zorbalığına etkisi. (Yayınlanmamış Doktora Tezi) İstanbul Üniversitesi Sağlık Bilimleri Enstitüsü, İstanbul.

Palladino, B. E., Nocentini, A. \& Menesini, E. (2016). Evidence-based intervention against bullying and cyberbullying: Evaluation of the NoTrap! Program in two independent trials. Aggresive \& Behavior, 42(2), 194-206. doi:10.1002/ab.21636

Patalay, P. \& Fitzsimons, E. (2017). Mental ill-health among children of the new century: Trends across childhood with a focus on age 14. London, UK: Centre for Longitudinal Studies.

Patchin, J.W. \& Hinduja, S. (2006). Bullies move beyond the schoolyard: A preliminary look at cyberbullying. Youth Violence and Juvenile Justice, 4(2), 148-169. 
Penning, S. L., Bhagwanjee, A. \& Govender, K. (2010). Bullying boys: The traumatic effects of bullying in male adolescent learners. Journal of Child \& Adolescent Mental Health, 22(2), 131-143. doi:10.2989/17280583.2010.528580

Pişkin, M. (2002). Okul zorbalığı: Tanımı, türleri, ilişkili olduğu faktörler ve alınabilecek önlemler. Kuram ve Uygulamada Eğitim Bilimleri, 2(2), 531-562.

Pişkin, M. (2003). Okullarımızda yaygın bir sorun: Akran zorbalığı. VII. Ulusal Psikolojik Danışma ve Rehberlik Kongresi Bildiri Özetleri. Malatya: İnönü Üniversitesi.

Quinn, S.T. \& Stewart, M.C. (2018). Examining the long-term consequences of bullying on adult substance use. American Journal of Criminal Justice, 43, 85-101. doi:10.1007/s12103-017-9407-5

Regel, S. \& Joseph, S. (2017). Post-traumatic stress. (2nd edition). Oxford University Press.

Rigby, K. (2007). Bullying in schools: And what to do about it. Camberwell: Acer Press.

Rigby, K. (2003). Stop the bullying: a handbook for schools. Melborne: Aust Council for Editional Research.

Rittakerttu, K.H., Matti, R., Paivi, R. \& Arja, R. (2000). Bullying at school-an indicator of adolescents at risk for mental disorders. Journal of Adolescence, 23(6), 661-674. doi:10.1006/jado.2000.0351

Serin, H. (2012). Ergenlerde siber zorbalık / siber mağduriyet yaşantıları ve bu davranışlara ilişkin öğretmen ve eğitim yöneticilerinin görüşleri. Doktora Tezi, İstanbul Üniversitesi Sos. Bil. Enst., İstanbul.

Shakoor, S., McGuire, P., Cardno, A.G., Freeman, D., Plomin, R. \& Ronald, A.R. (2015). A shared genetic propensity underlies experiences of bullying victimization in late childhood and self-rated paranoid thinking in adolescence. Schizophrenia Bulletin, 41, 754-763. doi:10.1093/schbul/sbu142

Silberg, J. L., Copeland, W., Linker, J. \& Moore, A.A. (2016). Psychiatric outcomes of bullying victimization: A study of discordant monozygotic twins. Psychological Medicine, 46(9), 1875-1883. doi:10.1017/\$0033291716000362

Stapinski, L. A., Bowes, L., Wolke, D., Pearson, R. M., Mahedy, L., Button, K. S., Lewis, G. \& Araya, R. (2014). Peer victimization during adolescence and risk for anxiety disorders in adulthood: A prospective cohort study. Depression \& Anxiety, 31(7), 574-582. doi:10.1002/da.22270

Takizawa, R., Maughan, B. \& Arseneault, L. (2014). Adult health outcomes of childhood bullying victimization: Evidence from a five-decade longitudinal British Birth Cohort. The American Journal of Psychiatry, 171(7), 777-784. doi:10.1176/appi.ajp.2014.13101401

Tehrani, N. (2004). Bullying: a source of chronic post traumatic stress? Journal British Journal of Guidance \& Counselling, 32(3), 357-366.

The WHO (2004). Cross-National Study of Health Behavior in School-Aged Children from 35 Countries: Findings from 2001-2002. Journal of School Health, 74(6), 204-206. doi:10.1111/j.1746-1561.2004.tb07933.x

Topçu, Ç. (2008). The relationship of cyber bullying to empathy, gender, traditional bullying, internet use and adult monitoring. (Yayınlanmamış Yüksek Lisans Tezi) Ortadoğu Teknik Üniversitesi Sosyal Bilimler Enstitüsü Eğitim Bilimleri Bölümü, Ankara.

Totan, T. ve Kabakçı, Ö. F (2010). İlköğretim ikinci kademe öğrencilerinde sosyal duygusal öğrenme becerilerinin zorbalığı yordama gücü. Uludağ Üniversitesi Eğitim Fakültesi Dergisi, 23(2), 575-600.

Totan, T. (2008). Ergenlerde zorbalığın anne, baba ve akran ilişkileri açısından incelenmesi. (Yayınlanmamış Yüksek Lisans Tezi). Abant İzzet Baysal Üniversitesi Sosyal Bilimler Enstitüsü Psikolojik Danışma ve Rehberlik Anabilim Dalı, Bolu.

Tsaousis, I. (2016). The relationship of self-esteem to bullying perpetration and peer victimization among schoolchildren and adoles-cents: A meta-analytic review. Aggression and Violent Behavior, 31, 186-199. doi:10.1016/j.avb.2016.09.005

Üneri, Ö. Ş. (2011). Çocuklarda akran zorbalığı. Düşünen Adam Psikiyatri ve Nörolojik Bilimler Dergisi, 24(4), 352-353.

Van Dam, D. S., Van der Ven, E., Velthorst, E., Selten, J.P., Morgan, C. \& De Haan, L. (2012). Childhood bullying and the associa-tion with psychosis in non-clinical and clinical samples: A review and meta-analysis. Psychological Medicine, 42, 2463-2474. doi:10.1017/S0033291712000360 
Van Geel, M., Vedder, P. \& Tanilon, J. (2014). Relationship between peer victimization, cyberbullying, and suicide in children and adolescents: A meta-analysis. Journal of the American Medical Association Pediatrics, 168, 435442. doi:10.1001/jamapediatrics.2013.4143

Van Geel, M., Goemans, A. \& Vedder, P.H. (2016). The relation between peer victimization and sleeping problems: A meta-analysis. Sleep Medicine Reviews, 27, 89-95. doi:10.1016/j.smrv.2015.05.004

Weaver, A. (2000). Can post-traumatic stress disorder be diagnosed in adolescence without a catastrophic stressor? A case report. Clinical Child Psychology and Psychiatry, 5(1), 77-83. doi:10.1177/1359104500005001008 